\title{
Structure and Growth of the Utricular Macula in the Inner Ear of the Slider Turtle Trachemys scripta
}

\author{
Stig Åvall Severinsen, ${ }^{1,2}$ Jørgen Mørup Jørgensen, ${ }^{2}$ and Jens Randel Nyengaard ${ }^{1}$ \\ ${ }^{1}$ Stereological Research Laboratory and Electron Microscopy Laboratory, University of Aarhus, DK-8000 Aarhus C, Denmark \\ ${ }^{2}$ Department of Zoophysiology, University of Aarhus, DK-8000 Aarhus C, Denmark
}

Received: 30 September 2002; Accepted: 18 April 2003; Online publication: 10 July 2003

\section{ABSTRACT}

In general, postembryonic production of inner ear vestibular hair cells (HCs) is believed to occur in all nonmammalian vertebrates. However, no study on this topic has been published on reptiles and, consequently, it is not known whether this also applies to these vertebrates. Therefore, the present study applied stereological methods in order to estimate the total number of HCs in turtles of varying sizes. The findings are that in prehatchlings the utricular macula (UM) contains $\sim 4000 \mathrm{HCs}$ as compared to $\sim 5000$ in juveniles, $\sim 8000$ in medium-sized turtles, and $\sim 12,000$ in large, sexually mature turtles. Scanning electron microscopy (SEM) reveals that presumably newly generated HCs with small surface areas and thin stereovilli are found in all regions of the UM. Furthermore, it reveals that utricular HCs can be classified as belonging to a specific region from the morphology of their apical structure. Striolar HCs have a large free oval-to-ovoid surface, a hair bundle with numerous stereovilli, and a short kinocilium. Rampary and cotillary HCs have smaller and slimmer free surfaces, comparatively fewer stereovilli, but much longer kinocilia. In conclusion, the current study demonstrates that postembryonic production of HCs does occur in reptiles and thereby supports the general view that this is a common trait in all nonmammalian vertebrates.

Keywords: hair cells, apical structure, reptile, development, stereology, striola

Correspondence to: Stig Åvall Severinsen, Ph.D • Streological Research Laboratory • Building $185 \cdot$ University of Aarhus - DK-8000 Aarhus C, Denmark - Telephone: +45 89422955; fax: + 45 89422952; email: stig.severinsen@IEKF.AU.DK

\section{INTRODUCTION}

All vertebrates possess hair cells (HCs) which function as transducers that transform mechanical stimuli into neurochemical signals. These HCs are found in both the lateral line of fish and aquatic amphibians as well as in vestibular and auditory sensory epithelia of the inner ear.

Inner ear vestibular HCs of amniote vertebrates have hitherto been divided into type I and type II, depending on their basolateral parts (Wersäll 1956). HCs I are generally large and amphora-shaped and enclosed by a nerve calyx, whereas HCs II are cylindrical in shape and innervated by bouton-shaped nerve endings. Apically, HCs have a hair bundle consisting of numerous stereovilli (which lack the typical axonema complex of a cilium and therefore are not cilia) and a true cilium, the so-called kinocilium. In addition to HCs, the sensory epithelium also consists of supporting cells (SCs) which are found between the HCs. In the utricular macula (UM), which is the largest of the vestibular end organs, the HCs show differences in apical surface area, hair bundle structure, and orientation, depending on the region in which they are found. The differentiation between such regions, of which there are three, was first made by Werner (1933), who divided the UM into a mediocentral cotillus, a lateral rampa, synonymous with pars interna and pars externa of Lindeman (1969a), and a striola, which is a narrow belt separating the two former regions. Striola was first described as a reinforcement of a stripe in the statoconial membrane which covers the UM, but later the sensory epithelium ventral to the stripe has been included in the term. In birds and reptiles, HCs I are exclusively found in striola (Rosenhall 1970; Jørgen- 
sen and Andersen 1973; Jørgensen 1974). In mammals, HCs I are widespread but their concentration is highest in striola (Lindeman 1969a). HCs II are found in all regions in all vertebrates examined.

Since HCs I and HCs II cannot be distinguished by their basal innervation in the scanning electron microscope (SEM), when studying the surface of the sensory epithelium, it is of great interest to determine if distinct HCs can be classified according to their apical structures only. To date, only the study of Peterson et al. (1996) has approached this issue in a detailed quantitative SEM analysis of the vestibular hair bundle structure in the posterior crista ampullaris of Trachemys. The findings were that variation of the hair bundle is both location-specific and typespecific, and they concluded that HCs I "probably bear significantly more stereocilia [stereovilli] than central type II hair cells."

Secondly, another topic which has not attracted much attention is whether postembryonic production of HCs occurs in the inner ear of reptiles as is the case in elasmobranchs (Corwin 1983, 1985a), bony fishes (Popper and Hoxter 1984; Mathiesen 1985; Lombarte and Popper 1994), amphibians (Alfs and Schneider 1973; Lewis and Li 1973; Corwin 1985b), and birds (Jørgensen and Mathiesen 1988; Goodyear et al. 1999).

Thirdly, the rate and pattern with which sensory epithelia grow in reptiles are not known and are still to be analyzed.

Even though the need for more detailed information on this intriguing and ancient class has been articulated by many (e.g., Lindeman 1969a; Baird 1970; Popper and Hoxter 1984), current research papers on this subject confirm that the reptiles have been largely neglected. In conclusion, the knowledge of apical HC morphology is scarce and no study on postembryonic HC proliferation and growth in reptiles has previously been published. Therefore, the goals of this study are (1) to describe morphological differences in the apical structure of HCs in different regions of the UM and (2) to estimate the number of HCs and the area of the UM in turtles of varying sizes, in order to determine whether postembryonic HC proliferation and growth take place in reptiles or not.

\section{MATERIALS AND METHODS}

\section{Animals}

Slider turtles Trachemys scripta (Schoepff) (syn. Pseudemys or Chrysemys) were used. Prehatchlings were obtained from a population of slider turtles kept in the animal facilities of the Department of Zoophysiology, The University of Aarhus, Denmark. Eggs were incubated for nearly two months at $30^{\circ} \mathrm{C}$ in an incu- bator. All turtles were weighed and the ventral part of the shell (plastron length, $P L$ ) measured. Turtle embryos were removed from the eggs just before hatching and decapitated with a pair of scissors. Juvenile turtles were killed the same way, whereas the rest were decapitated in a guillotine. The lower jaw was removed and the head divided through the medial plane. After the brain was removed, the bony labyrinth was opened in order to prepare the membranous labyrinth for fixation.

All animals were handled in accordance with NIH rules. Permission to import the animals were given by the Danish Veterinary and Food Administration and by the National Forest and Nature Agency, Denmark.

\section{Preparation of UM for SEM}

Two different methods were applied in order to study the apical structures and pattern of the sensory epithelium in the utricle in SEM.

Hair bundle morphology. First, otofixation [a modified version of the method described by Malick and Wilson (1975)] was applied to study the structure of the hair bundle on the HCs. Six turtles with $P L$ between 3.1 and $20.4 \mathrm{~cm}$ were studied. Specimens were fixed in a mixture of $2 \mathrm{ml} 25 \%$ glutaraldehyde, $23 \mathrm{ml} 0.1 \mathrm{M}$ cacodylate buffer, $25 \mathrm{mg}$ ruthenium red, and $10 \mathrm{mg} \mathrm{MgCl}_{2}$ (pH 6.0) and placed in a rotator for at least $1 \mathrm{~h}$. The semicircular canals were transsected and the entire membranous labyrinth was gently removed from the ossified labyrinth by pulling the vestibulocochlear nerve. After a rinse in $0.1 \mathrm{M}$ cacodylate buffer, the specimen was put in $3 \%$ osmium tetroxide in $0.1 \mathrm{M}$ cacodylate buffer for $1 \mathrm{~h}$. A thorough rinse in distilled water followed, after which the specimen was placed in a saturated $(\sim 1 \%)$ solution of thiocarbohydrazide (TCH). Yet another thorough rinse in distilled water was followed by $30 \mathrm{~min}$ in $1 \%$ osmium tetroxide in distilled water, a third rinse in distilled water, $\mathrm{TCH}$ for $30 \mathrm{~min}$, a fourth rinse in distilled water, $1 \%$ osmium tetroxide in distilled water for $30 \mathrm{~min}$, and, finally, a fifth rinse in distilled water followed by $5 \mathrm{~min}$ in $50 \%$ alcohol. Specimens were then dissected in $70 \%$ alcohol. The thin crescentshaped "roof" covering the UM was cut away with surgical scissors and the statolith removed. To remove superfluous cupular matrix material and loose statoconial crystals, the sensory epithelium was repeatedly rinsed by injecting squirts of $70 \%$ alcohol. After dehydration in a graded series of alcohol followed by acetone, specimens were first critical point dried in an EMS 850 Critical Point Drier, then sputter coated with platinum for $4 \mathrm{~min}$ in an Edwards S $150 \mathrm{~B}$ Sputter Coater, and finally mounted on stubs. Scanning was conducted with a CamScan MaXim 2040 EnVac scanning electron microscope (CamScan 
Electron Optics Ltd, Cambridge, UK) controlled by the program MaXim 4, which was also used to capture micrographs digitally.

Apical HC surface. Second, to study the position of the kinocilium relative to the stereovilli and the number of stereovilli, 7 specimens with PL between 6.0 and $17.6 \mathrm{~cm}$ were fixed in $3 \%$ glutaraldehyde, rinsed in phosphate buffer, and postfixed in osmium tetroxide for $1 \mathrm{~h}$. After $24 \mathrm{~h}$ in $70 \%$ alcohol, the specimens were sonicated in a Metason 1500 sonicator for 1-10 min to remove hair bundles and microvilli. After dehydration in a graded series of alcohol, specimens were first vacuum dried for at least 1 $\mathrm{h}$ in a MAXI Vacuum Dryer, then sputter coated for 4 min, and finally mounted on stubs. The number of stereovilli per HC was estimated from micrographs (magnification 5000×) taken on a JSM 840 scanning electron microscope.

\section{Light microscopy (LM)—plastic sections}

For plastic sections, 12 turtles with $P L$ between 2.8 and $22.0 \mathrm{~cm}$ were fixed as described above. After dehydration, specimens were embedded in Epon 812 and left in a $60^{\circ} \mathrm{C}$ oven for 2 days. Sections of $1-2 \mu \mathrm{m}$ were cut with glass knives on a JUNG microtome and stained with toluidine blue for 3-5 min.

\section{Preparation of whole mounts}

For whole mounts, 26 turtles with $P L$ between 2.8 and $22.2 \mathrm{~cm}$ were prepared as described above and stored in $70 \%$ alcohol. The dense nerve plexus emanating from the vestibulocochlear nerve was then gently removed and the specimens were dehydrated in a graded series of alcohol. After $10 \mathrm{~min}$ in xylene, specimens were whole-mounted on slides using XAM neutral medium and left in a $40^{\circ} \mathrm{C}$ oven overnight.

\section{Sampling equipment: Setup for whole-mount preparations}

A digital image of the microscope field was taken with a JVC 3-CCD KY-F55B color video camera and viewed on an EIZO FlexScan F930 monitor, on which a counting frame was superimposed by the software CAST 2.0 (Olympus Denmark A/S) and a frame grabber (FlashPoint 3D Plus), running on a Dell OptiPlex GX 110 computer. The contour of the UM was drawn at a final absolute magnification of $2099 \times$ with a $60 \times$ PlanApo oil immersion objective $(\mathrm{NA}=1.40)$. The border of striola was drawn in the same manner, following both the medial and the lateral edges of the HCs I. The ability to focus in the $z-$ axis plane while simultaneously determining the border allowed for exact differentiation between HCs and transitional epithelium as well as between HCs I and HCs II.

Estimation of number of HCs and area from whole mount preparations: Applied stereology

In order to estimate the total number of HCs per macula and the total area of sensory epithelium per macula, some basic 2D stereological techniques were applied. The whole-mounted specimen was fixed on the motorized stage of an Olympus BX50 light microscope, which allowed exact movements along the $x$ and $y$ axes. Estimation of the number of HCs was conducted on all extrastriolar HCs and on striolar HCs I. Since the nerve plexus penetrating the basal lamina as well as the connective tissue ventral to striola often blocked much of the light, the number of HCs II in striola was not estimated as individual HCs were very difficult to identify. This resulted in an estimate of the total HC population which was $\sim 3 \%-$ $6 \%$ lower than the actual value, since a $55 \%$ distribution of HC I and HC II was estimated for two small, two medium-sized, and two large turtles, in which a distinction between HCs I and II was possible due to perfect dissection and staining.

The total number of HCs for each macula was estimated by means of the 2D fractionator (Gundersen 1986) combined with a 2D unbiased counting rule (Gundersen 1977) which implies counting both HCs located completely within a counting frame and those intersected by inclusion lines (dark) but not by any of the exclusion lines (light) (Fig. 1). Starting from a random position chosen by CAST 2.0 and moving in exact steps ( $d x$ and $d y$ ), the unbiased counting frame with a known area $a$ (frame) was moved along the $x$ or $y$ axis so that the entire section was covered in a meandering fashion. As a result, the UM was systematically, uniformly, randomly sampled by the sampling fraction ( $s f$ ) which equals the area of the counting frame divided by the sampling area $d x \times d y$ :

$$
\frac{s f=a(\text { frame })}{d x \times d y}
$$

Multiplying the inverse sampling fraction $(1 / s f)$ by the total number of HCs counted with each counting frame $\left(Q^{-}\right)$yielded an unbiased estimate of the total number of HCs $(N)$ in the entire UM:

$$
N=\frac{d x \times d y}{a(\text { frame })} \times \Sigma Q^{-}
$$

A counting frame size of $815.8 \mu \mathrm{m}^{2}$ and a $d x-d y$ step distance of $100 \mu \mathrm{m}$ were chosen to optimize data collection. In juvenile turtles $(P L<10 \mathrm{~cm})$, HCs were counted in a frame of size $8152.8 \mu \mathrm{m}^{2}$ in both the rampary and the striolar regions. In larger turtles, this large frame was applied only to the striolar region. 


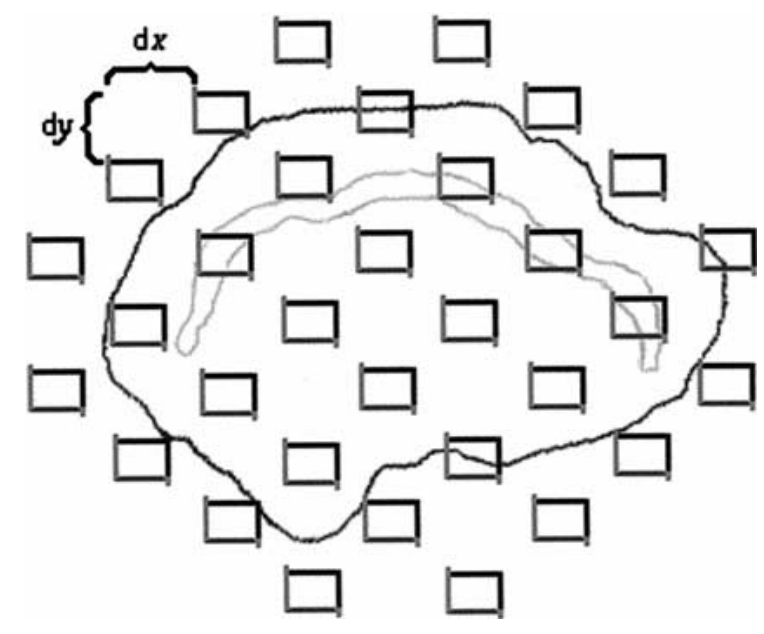

FIG. 1. The 2D fractionator principle. Unbiased counting frames are merged with a digital image of the outlined utricular macula (UM) and viewed on a TV monitor. Since the first counting frame is placed randomly and succeedingly systematically displaced by $d x$ or $d y$, this is systematic, uniform random sampling. The step length equals $100 \mu \mathrm{m}$. The narrow crescent band represents the outline of striola. It should be noted that this figure does not represent real proportions as the counting frames used in the present study were relatively smaller. Approximately 45-140 frames were applied on each macula, depending on the actual size of the sensory epithelium.

This procedure was choosen to optimize sampling after a "do more less well" principle (Gundersen and Østerby 1981).

\section{Sampling variance}

Sampling variance $(C E=\mathrm{SEM} /$ mean $)$ for numberweighted sampling of objects is related to the independent variance of the stereologic counting procedure, noise, and the contribution from systematic, uniform, random sampling (SURS) (Gundersen et al. 1999; Nyengaard 1999). As a low sampling fraction was taken from whole mounts, the $C E$ was approximated as:

$$
C E=\frac{1}{\sqrt{\Sigma Q^{-}}}
$$

The mean $C E$ for each of the regions was rampa $=4 \%$, striola $=6 \%$, and cotillus $=5 \%$.

\section{Area estimation of the three regions in the UM}

The total area $(A)$ of each region was estimated by counting test points $(p)$ covering the sensory epithelium. This task was performed while counting HCs. In the small counting frame, the four corners served as test points $(p=4)$, whereas 25 evenly distributed test points were used on the large frame $(p=25)$. The area of each region was estimated as follows:

$$
A=\frac{d x \times d y}{p} \times \Sigma P
$$

where $P$ equals the total number of test points counted in each region. The total area of the sensory epithelium was calculated by adding the areas of the three regions.

\section{Statistical methods and analyses}

An ANOVA test was performed on the area fraction, and an all-pairwise multiple comparison procedure (Student-Newman-Keuls method) was used to isolate groups that had a mean value significantly different from the others. Since variances of the number of stereovilli and mean area per HC were heteroscedastic, a nonparametric Kruskal-Wallis one-way analysis of variance on ranks was used. To isolate the group or groups that differed from the others, the StudentNewman-Keuls method was applied. The regression lines were treated and calculated as "orthogonal" regression lines (Ricker 1973). The slopes in Figures $6 \mathrm{~b}, 6 \mathrm{~d}$, and $7 \mathrm{~b}$ were compared using the statistical package version 6.12 (SAS Institute Inc., Cary, NC, USA). The level of significance was $2 P<0.05$.

Results are shown as mean value (mean), coefficient of variance $(\mathrm{CV}=\mathrm{SD} /$ mean $)$, and number of animals $(n)$.

\section{RESULTS}

Gross morphology of the inner ear

The inner ear may be divided into an upper and a lower part named pars superior and pars inferior (Fig. 2b). Pars superior consists of three semicircular canals, each containing an otic ampulla. Each ampulla contains a crista ampullaris with a sensory epithelium. Ventrally, between the anterior and the lateral ampullae, is the utricular recess which contains the sensory epithelium macula utriculi (UM). Pars inferior is basically one large sac containing three sensory organs: the lagenar macula, the saccular macula, and the basilar papilla.

\section{General structure of the UM}

The sensory epithelium in the UM consists of SCs, HCs, and nerve fibers. In the SC, the nucleus is basally located and the cell itself spans the entire epithelium. Apically, it has microvilli and a short cilium, the so-called ciliary rod. There are two main types of HCs. The HC I is amphora shaped and basolaterally 


\section{a}
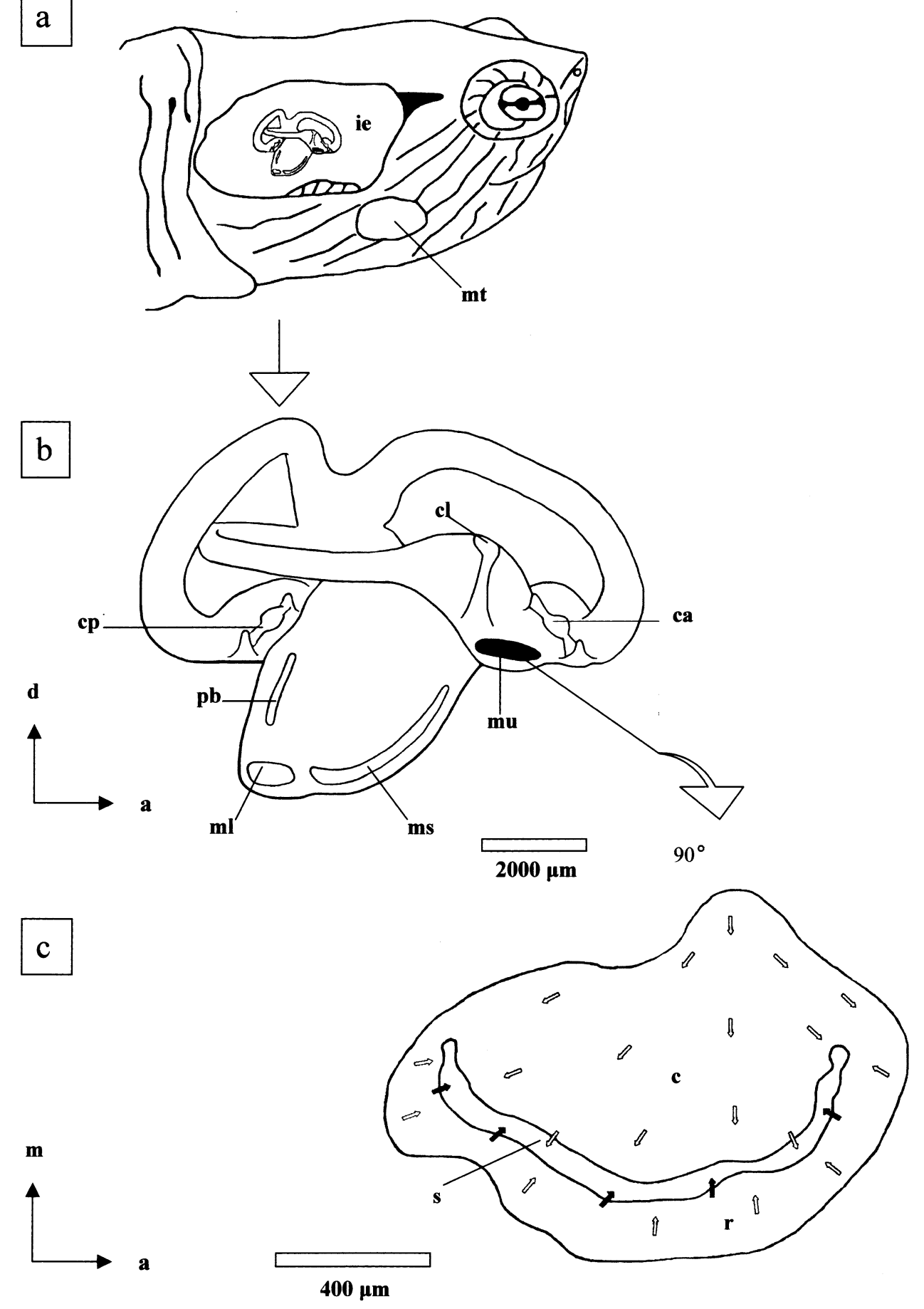

FIG. 2. a. The position of the inner ear (ie) and the tympanic membrane (mt) is shown. b.

Lateral view of the inner ear and the positions of the end organs are shown. ca: crista anterior; cl: crista lateralis; cp: crista posterior; ml: macula lagenae; ms: macula sacculi; mu: macula utriculi; pb: papilla basilaris; d: dorsal direction; a: anterior direction. Pars superior consists of the three semicircular canals and contains the three cristae and macula utriculi. Pars inferior is the lower saclike structure which contains the three other end organs. c. The outline of the utricular macula (UM). Arrows indicate the orientation of the hair cells (HCs) with respect to the position of the kinocilium in relation to the stereovilli. Dark arrows indicate striolar HCs which are oriented toward the medial edge. c: cotillus; r: rampa; s: striola; $\mathrm{m}$ : medial direction; a: anterior direction.

enclosed by a nerve calyx. Up to 8 HCs I have been observed to be enclosed in such a calyx, 2-4 being most common. HC II is cylindrical in shape and innervated by bouton-shaped nerve endings.

\section{Regional differentiation of the UM}

The UM is divided into three regions (Fig. 2c). The centromedial region is termed the cotillus and makes up $62.6 \%$ of the total area (0.06) [53.8\%-70.1\%] $n=26$, (mean (CV) [min-max] n). Along the lateral edge of the UM, extending from its anterior to its posterior edge, runs the narrow belt named striola. When observed in SEM, striola is defined by oval HCs with thick hair bundles and a short kinocilium. When observed in LM, striola is characterized by the nerve calyx which appears as a grayish-white ring around the HCs I. Furthermore, the epithelium is higher in 
this part, so the surface is slightly elevated compared with the rest of the epithelium. It makes up $8.1 \%$ of the total area $(0.24)$ [5.2\%-11.5\%] $n=26$, and is $6-$ 10 HCs wide in cross section. In both the anterior and posterior parts of striola, the belt is very narrow and often only 1-2 HCs wide. The third region, termed rampa, runs along the peripheral border of striola. It makes up $29.4 \%$ of the total area $(0.11)$ [23.2\%$36.4 \%] n=26$, and is $10-15$ HCs wide in cross section. HCs II are found in all regions, whereas HCs I are found only in striola.

\section{Orientation of HCs}

Since the single kinocilium is located outside the bundle of stereovilli, the HCs are morphologically orientated according to their hair bundle (Fig. 2c). In cotillus, the HCs radiate anteriorly, laterally, and posteriorly from the medial edge, with their kinocilia placed on the lateral side of the stereovilli. This is also the case for the HCs in striola, even though their exact orientation on the outer edge is less well defined, since some HCs in striola are probably oriented toward the medial edge (Fig. 2c, dark arrows). In rampa, the HCs have their kinocilia on the medial side of the stereovilli and are thus oriented toward the medial edge. The HCs are thus arranged in a fanshaped bidirectional pattern emanating from the medial edge of cotillus (Fig. 2c). The surface of the SCs can be either narrow or broad and follow the fanshaped pattern of the HCs in their orientation according to their length axis.

\section{Apical HC morphology}

Based on their apical structure, the HCs can be divided into cotillary, striolary, and rampary HCs (Fig. 3a-f). Cotillary HCs (type II) are generally slim and cigar-shaped and quite equal in size (Fig. 3e, f). The kinocilium is approximately $7-13 \mu \mathrm{m}$ high and the stereovilli are arranged in 7-12 rows with 4-6 stereovilli in each, adding up to a total of $44.0(0.16)$ (mean (CV)). The striolar HCs (types I and II) vary much in size but are all oval to ovoid in apical shape and contain a large free elevated surface (Fig. 3c, d.). A clear difference between HCs I and HCs II has not been determined but the HCs with large surfaces are most probably HCs I. The kinocilia are relatively short with lengths of approximately $5-7 \mu \mathrm{m}$. The stereovilli are arranged in 8-10 rows with 5-12 stereovilli in each, adding up to a total of $67.0(0.26)$. HCs with up to 140 stereovilli in each bundle can be observed in striola. Rampary HCs (type II) appear a little shorter and more rounded than the cotillary HCs but not as oval as the striolar HCs (Fig. 3a, b). In size and apical structure they much resemble cotillary HCs. The kinocilium is approximately $8-11 \mu \mathrm{m}$ long and the stereovilli are arranged in $6-10$ rows with $5-7$ stereovilli in each, adding up to a total of $38.4(0.17)$ per bundle.

\section{Small HCs}

HCs with a much smaller apical surface than the average are found in all three regions. An example of this is illustrated in Figure 4. All small HCs have stereovilli which are thinner and shorter than stereovilli on "normal" mature HCs. Also, the kinocilia are often very short and in some cases resemble the ciliary rods. Furthermore, the height of both the stereovilli and the kinocilia varies in different small HCs. Some of the HCs are very small, whereas others are medium-sized. This grading of small HCs is illustrated in Figure 5. Surprisingly, even the kinocilium appears thinner in these small HCs than in larger HCs.

\section{Total number of $\mathrm{HCs}$ and $P L$}

The total number of HCs of the UM and the total number of HCs in cotillus, rampa, and striola are positively correlated to the square root of the $P L$ (Fig. $6 a, b)$.

\section{Total number of HCs and area of the UM}

The total number of HCs of the UM is positively correlated to the area of the UM (Fig. 6c). Likewise, the total number of HCs in each region is positively correlated to the area of cotillus, rampa, and striola (Fig. 6d). The area of the UM shows a positive correlation to the square root of the PL (Fig. 7a). Likewise, there exists a positive correlation between the area of cotillus, rampa, and striola and the square root of the $P L$ (Fig. 7b).

Area fraction of cotillus, rampa, and striola in turtles of varying $P L$

The area fraction as a function of the square root of the $P L$ shows that the three regions remain constantly independent of $P L$ (Fig. 7c). The average area fraction is $A F$ (cotillus) $=62.6 \%, A F($ rampa $)=29.4 \%$, and $A F($ striola $)=8.1 \%$.

\section{Mean area per $\mathrm{HC}$ and $P L$}

The mean area occupied by each $\mathrm{HC}$, including its surroundings (i.e., the apical surface of the SCs), in each region of the UM was calculated as the total area of the UM divided by the total number of HCs and is 

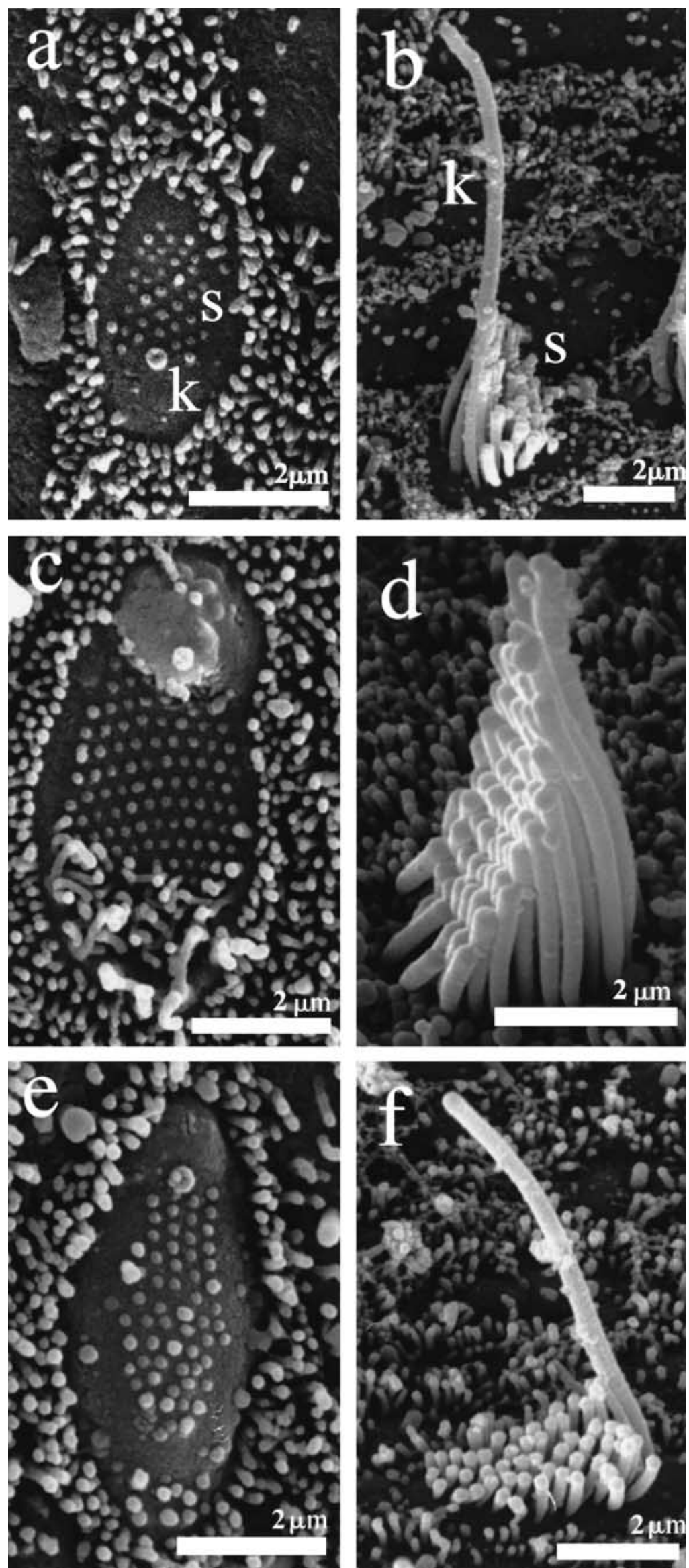

FIG. 3. Hair cells (HCs) from the three regions of the utricular macula (UM). Scanning electron microscope (SEM) micrographs $\mathbf{a}, \mathbf{c}$, and $\mathbf{e}$ are seen perpendicular to the surface. The hair bundles have been removed. Micrographs $\mathbf{b}, \mathbf{d}$, and $\mathbf{f}$ are seen from the side at some inclination and show HCs with intact hair bundles. a, b. Rampary HCs. c, d. Striolar HCs. e, f. Cotillary HCs. k: kinocilium; s: stereovilli. 


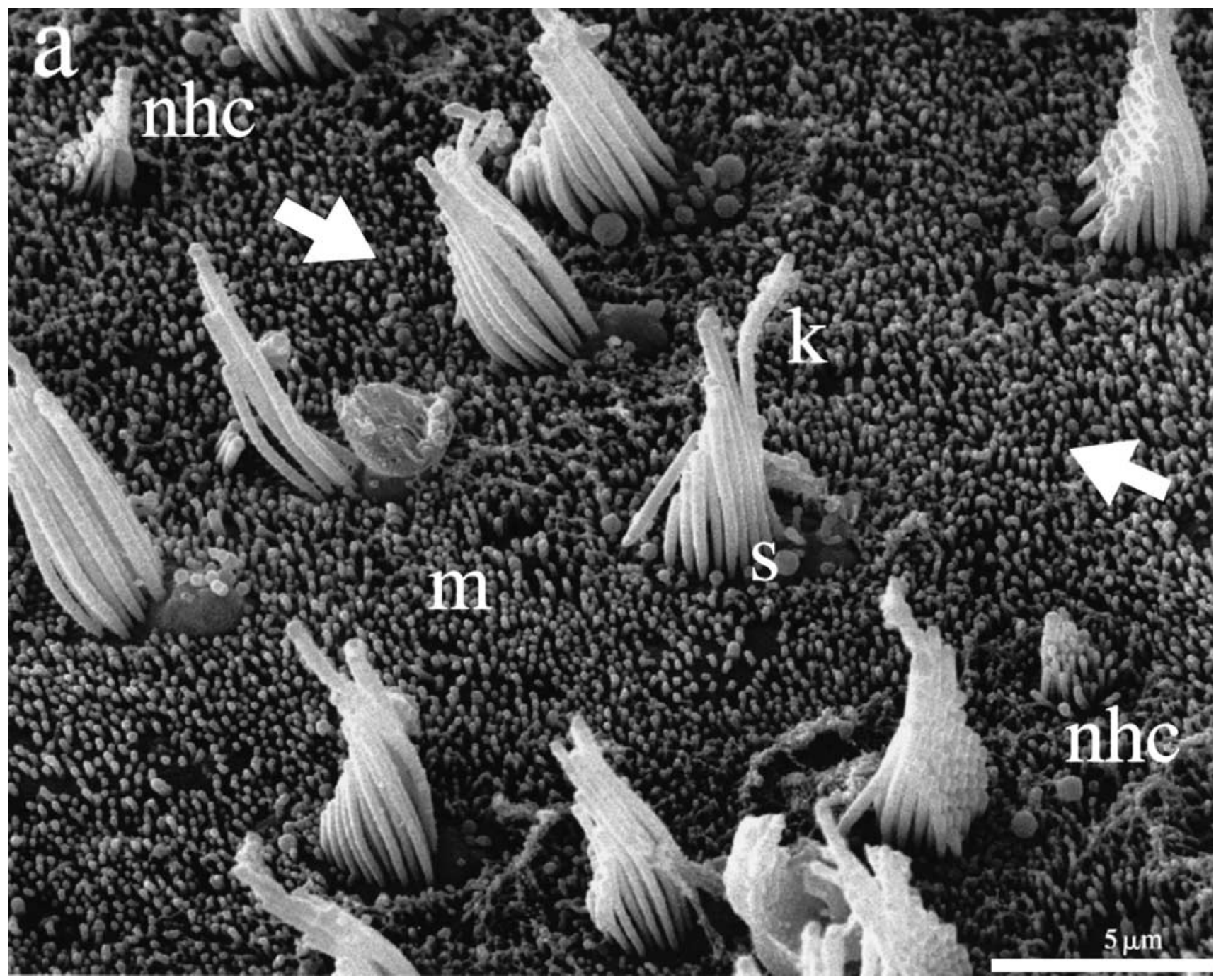

FIG. 4. Scanning electron microscope (SEM) micrograph of the dividing line in striola of a large, sexually mature turtle. Note that the small new hair cells (nhc) bear thin stereovilli. Also note the thickness of the hair bundles on the larger HCs which are oppositely oriented as indicated by arrows, k: kinocilium; s: stereovilli; m: microvilli.

shown in Figure $7 \mathrm{~d}$. The striolar HCs occupy the largest area $\left(141 \mu \mathrm{m}^{2}(0.20)\right.$ [86-199 $\left.\mu \mathrm{m}^{2}\right]$ ) (mean (CV) $[\min -\max ])(2 P<0.05)$, meaning that $\mathrm{HC}$ numerical density in this region is lowest. The rampary HCs $\left(80 \mu \mathrm{m}^{2}(0.17)\left[54-110 \mu \mathrm{m}^{2}\right]\right)$ and the cotillary HCs $\left(89.4 \mu \mathrm{m}^{2}(0.14)\right.$ [65-120 $\left.\left.\mu \mathrm{m}^{2}\right]\right)$ claim approximately an equal area even though they are also significantly different $(2 P<0.05)$, meaning that $\mathrm{HC}$ densities in rampa are highest.

\section{DISCUSSION}

Gross morphology of the inner ear

The gross morphology of the reptilian inner ear has previously been described by Retzius (1884)Burlet (1934)Baird (1970), and Jørgensen (1974), and the present study is in full accordance with former descriptions.

\section{General structure of the UM}

The general structure of the sensory epithelium is similar to that of other amniotes, with SCs resting on a basal membrane and spanning the entire epithelium (Lindeman 1969b; Jørgensen 1981, 1989) and with HCs types I and II shaped and innervated as first described by Wersäll (1956). Furthermore, the orientation of the HCs is also similar to the well-known fan-shaped pattern found in all vertebrates (Flock 1964; Lindeman 1969a; Rosenhall 1970; Jørgensen $1974,1975,1981)$. However, the present study on the fine structure and distribution of HCs reveals that the $\mathrm{UM}$ of the slider turtle in some aspects differs from 

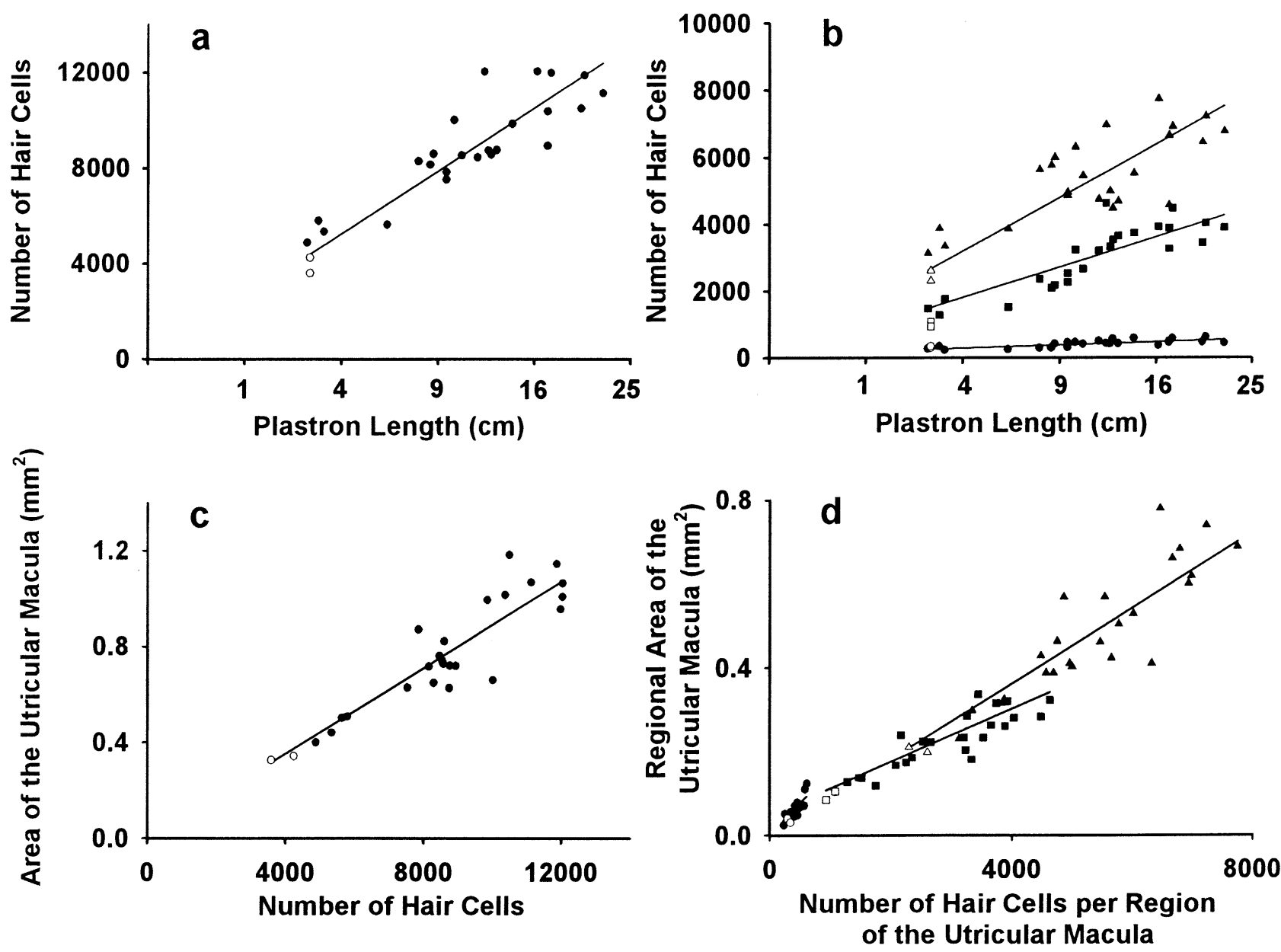

FIG. 6. a. The positive correlation between the number of hair cells $(\mathrm{HCs})$ and the square root of the plastron length $(P L)$ is shown. The observed regression line $\left(r=0.90 ; 2 P=2.5 \times 10^{-10}\right)$ is described by the equation $N(H C)=2619 \sqrt{P L}$, where $N(H C)$ is the number of HCs. Open symbols represent prehatchlings. b. The positive correlation between the total number of hair cells (HCs) and the square root of the plastron length $(P L)$ in cotillus $(\mathbf{\Delta})$, rampa $(\mathbf{\square})$, and striola $(\mathbf{O})$ is shown. The observed regression line for cotillus $(r=0.81,2 P=4.2 \times$ $\left.10^{-7}\right)$ is described by the equation $N(\mathrm{HC}$, cotillus $)=1565 \sqrt{P L}$. The observed regression line for rampa $\left(r=0.90,2 P=5.3 \times 10^{-10}\right)$ is described by the equation $N(\mathrm{HC}$, rampa $)=1158 \sqrt{P L}$. The observed regression line for striola $\left(r=0.74,2 P=1.5 \times 10^{-5}\right)$ is described by the equation $N(\mathrm{HC}$, striola $)=114 \sqrt{P L}+145$. The regression line intersects the $x, y$ axes significantly far from the origo $(2 P=0.01)$. Open symbols represent prehatchlings: $\mathbf{c}$. The positive correlation

functional clues. Even though neither fish nor amphibians contain HCs I in the inner ear (Jørgensen 1981), it can be concluded that the number of stereovilli per HC seems to be rather similar in anamniotes and amniotes.

As in the turtles, the shortest kinocilia are also found in striola of bullfrogs, reptiles, and chinchillas (Lewis and Li 1975; Jørgensen 1988; HunterDuvar 1983).

between the total number of hair cells (HCs) and the total area of the utricular macula $(\mathrm{UM})$ is shown. The observed regression line $\left(r=0.92,2 P=4.6 \times 10^{-11}\right)$ is described by the equation $A(\mathrm{UM})=92.8 \times 10^{-6} \times \mathrm{N}(\mathrm{HC})$, where $A(\mathrm{UM})$ is measured in $\mathrm{mm}^{2}$. Open symbols represent prehatchlings. $\mathbf{d}$. The number of hair cells (HCs) in each region is positively correlated to the area of cotillus $(\mathbf{\Delta})$, rampa $(\mathbf{\square})$, and striola $(\mathbf{O})$. The regression line for striola $(r=0.83$, $\left.2 P=1.3 \times 10^{-7}\right)$ and the regression line for cotillus $(r=0.91$, $\left.2 P=2.1 \times 10^{-10}\right)$ are fit by the equation $A(\mathrm{UM}$, striola $)=173 \times 10^{-6}$ $\times N(\mathrm{HC})$ and $A(\mathrm{UM}$, cotillus $)=101 \times 10^{-6} \times N(\mathrm{HC})$. The regression line for rampa $\left(r=0.90,2 P=6.0 \times 10^{-6}\right)$ does not intersect the origo $(2 P=0.03)$, which yields the following equation: $A(U M$, rampa) $=0.043+62.3 \times 10^{-6} \times N(\mathrm{HC})$. The regression line for striola has a slope significantly different from that of cotillus $(2 P=0.046)$ and rampa $(2 P=0.0008)$. Open symbols represent prehatchlings.

In conclusion, short kinocilia on striolar HCs seems a common trait in lower and higher vertebrates.

\section{Definition of striola}

The term striola, which means "little stripe," was coined by Werner (1933). Originally, he defined striola as a reinforced band on what he called the "macularium" (synonymous with the statolith), but 

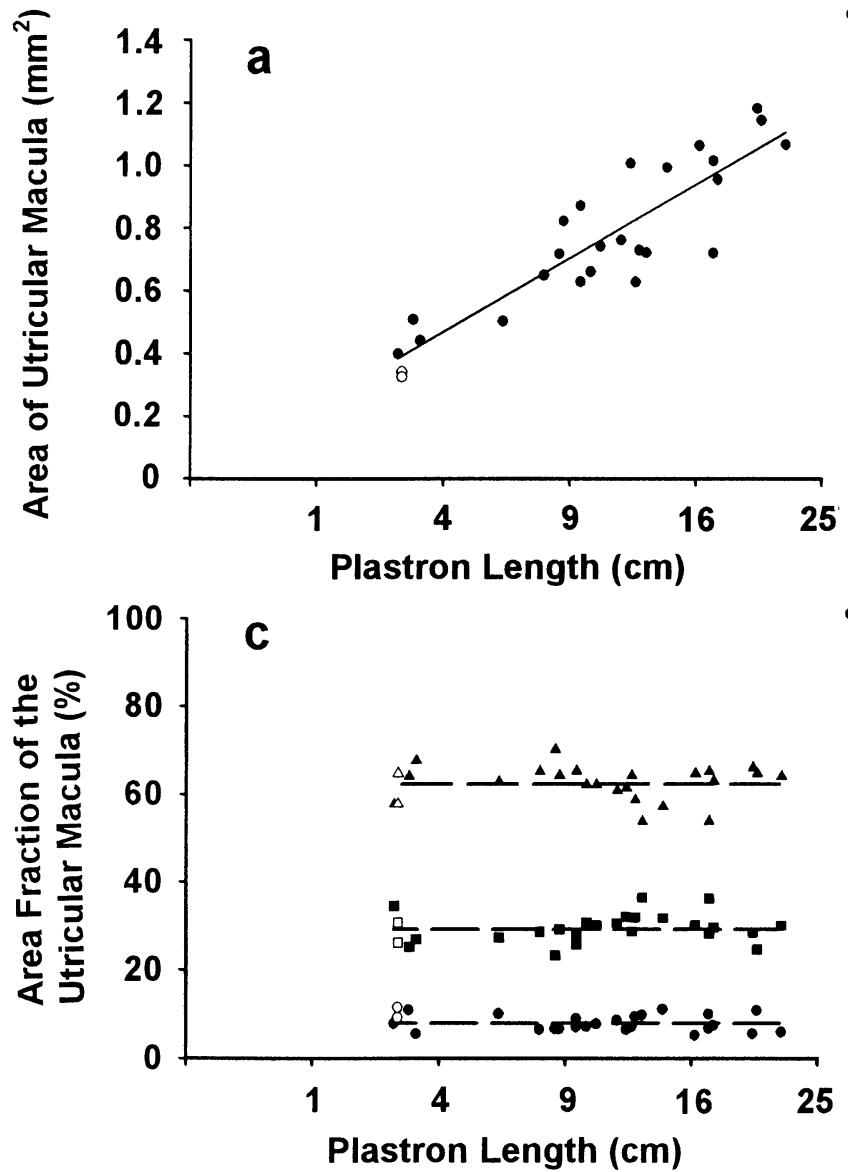

FIG. 7. a. The positive correlation between the area of the utricular macula (UM) and the square root of the plastron length $(P L)$ is shown. The observed regression line $\left(r=0.90,2 P=5.1 \times 10^{-10}\right)$ is fit by the equation $A(\mathrm{UM}) \mathrm{mm}^{2}=0.027 \mathrm{~mm}^{2} \times \mathrm{cm}^{-1 / 2} \sqrt{P L(\mathrm{~cm})}$. Open symbols represent prehatchlings. b. The positive correlation between the area of the utricular macula (UM) and the square root of the plastron length $(P L)$ for cotillus $(\boldsymbol{\Lambda})$, rampa $(\boldsymbol{\square})$, and striola $(\mathbf{O})$ is shown. The observed regression line for cotillus $(r=0.85,2 P=3.0 \times$ $\left.10^{-8}\right)$ is described by the equation $A\left(U M\right.$, cotillus) $\mathrm{mm}^{2}=0.17 \mathrm{~mm}^{2}$ $\times \mathrm{cm}^{-1 / 2} \sqrt{P L(\mathrm{~cm})}$. The observed regression line for rampa $(r=0.91$, $\left.2 P=1.9 \times 10^{-10}\right)$ is described by the equation $A(U M$, rampa) $\mathrm{mm}^{2}=0.08 \mathrm{~mm}^{2} \times \mathrm{cm}^{-1 / 2} \sqrt{P L(\mathrm{~cm})}$. The observed regression line for striola $(r=0.68,2 P=0.0001)$ is described by the equation $A\left(\mathrm{UM}\right.$, striola) $\mathrm{mm}^{2}=0.024 \mathrm{~mm}^{2} \times \mathrm{cm}^{-1 / 2} \sqrt{P L(\mathrm{~cm})}$. In addition, the regression line does intersect the $x, y$ axes significantly far from the origo $(2 P=0.54)$. Open symbols represent prehatchlings. $\mathbf{c}$. The regional area fractions. There is no correlation between the area

later he expanded the definition to include the underlying sensory epithelium as well. In the present study, only the latter meaning is applied, but this does not make things more simple. Depending on the method used when investigating striola, it can be defined by different criteria such as HC orientation, apical HC structure, level and thickness of the cuticular plate, basal innervation of the HCs, vertical position of the nuclei, and HC body shape seen in transverse section.
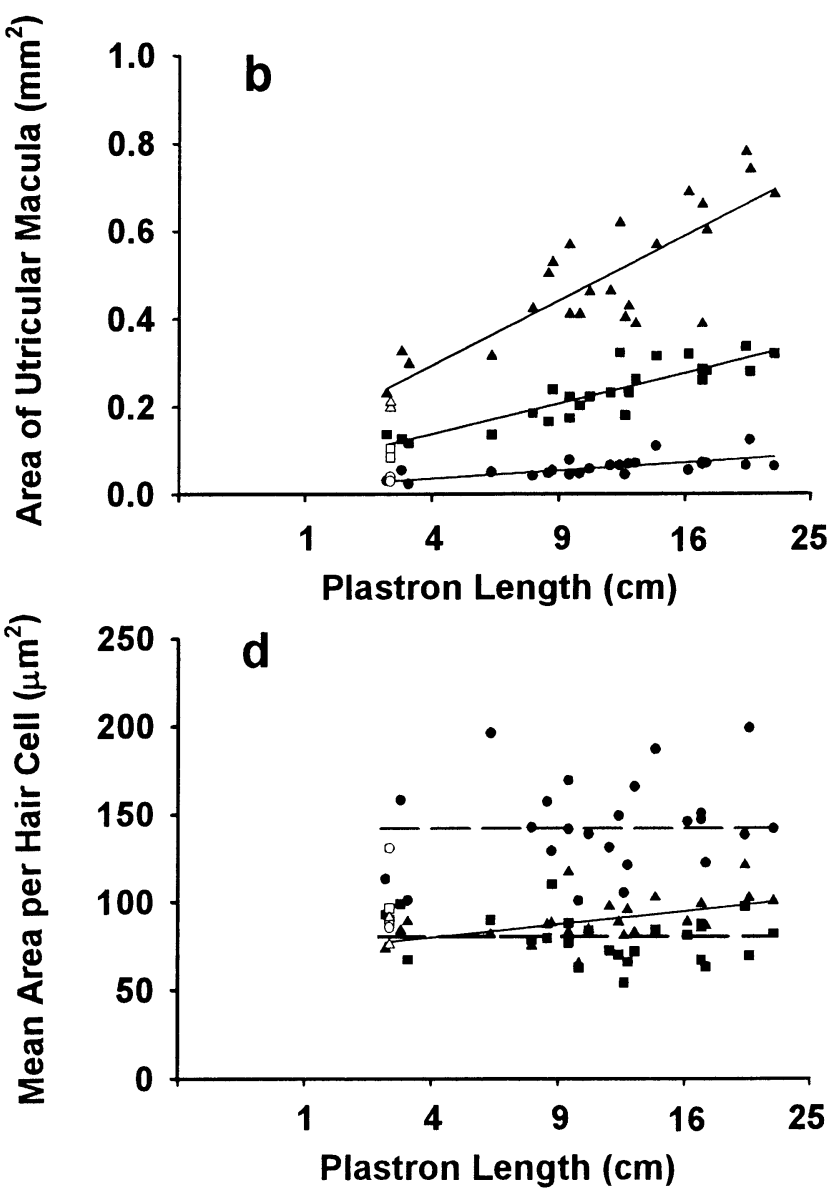

fraction of cotillus $(\mathbf{\Delta})$, rampa $(\mathbf{\square})$, and striola $(\mathbf{O})$ and the square root of the plastron length $(P L)$, but they are all significantly different from each other $(2 P<0.05)$. The average area fraction is $A F$ (cotillus $)=62.6, A \mathrm{~F}($ rampa $)=29.4$, and $A \mathrm{~F}($ striola $)=8.1$. Open symbols represent prehatchlings. $\mathbf{d}$. The mean area claimed per hair cell $(\mathrm{HC})$ in cotillus $(\mathbf{\Delta})$, rampa $(\boldsymbol{\square})$, and striola $(\mathbf{O})$ versus the square root of the plastron length $(P L)$ is shown. The striolar HCs claim the largest area $\left(141 \mu \mathrm{m}^{2}(0.20)\right.$ [86-199 $\left.\left.\mu \mathrm{m}^{2}\right]\right)$ (mean (CV) [min-max]) $(2 P<$ 0.05). The rampary HCs $\left(80 \mu \mathrm{m}^{2}(0.17)\left[54-110 \mu \mathrm{m}^{2}\right]\right)$ and the cotillary HCs $\left(89.4 \mu \mathrm{m}^{2}(0.14)\left[65-120 \mu \mathrm{m}^{2}\right]\right)$ claim about the same area, even though they are also significantly different $(2 P<0.05)$. The lines describing $\mathrm{HC}$ area possession $(A P)$ versus $P L$ in striola and rampa are $A P(\mathrm{~s})=141$ and $A P(\mathrm{r})=80$. The slope of inclination for the line describing the area possessed per $\mathrm{HC}$ in cotillus is significantly different from zero $(r=0.49,2 P=0.01)$, which yields the equation $A P\left(\mathrm{c}, \mu \mathrm{m}^{2}\right)=13.54 \mu \mathrm{m}^{2} \times \mathrm{cm}^{-1 / 2}+68$. Open symbols represent prehatchlings.

When observed in LM, only HCs I can be used as indicators of striola, which undoubtedly underestimates the actual striolar width, since marginal HCs II belonging to striola cannot be distinguished from extrastriolar HCs II. The inability to recognize the hair bundle of all HCs in LM is the Achilles' heel of this method.

Defining striola through observation of the nerve calyx which surrounds HCs I results in striola that is 6-10 HCs I wide in cross section when observed in 
FIG. 8. a. Information on total hair cell $(\mathrm{HC})$ number and total area of the utricular macula (UM) in animals from different classes, subclasses, and order, studied by different investigators using varying techniques. Both axes are logarithmic. The regression line $(r=0.94,2 P=3.97 \times$ $\left.10^{-12}\right)$ is fit by the equation $\log \mathrm{UM}\left(\mathrm{mm}^{2}\right)=-4.44+1.06 \log \mathrm{HC}$. The various animal classes are illustrated by the following symbols: ( $\bullet$ fish

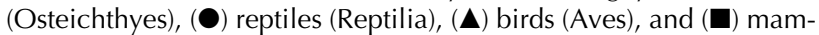
mals (Mammalia). Open circles $(\mathrm{O})$ represent three stages of Trachemys. The figure is based on the following species and stages of animals listed from the lowest to the highest number of HCs: Myotis daubentonii, mean value of 4 animals (Kirkegaard and Jørgensen 2001); Anguilla anguilla (Glass eel) (Mathiesen 1985); Sorex araneus, mean value of 4 animals (Kirkegaard and Jørgensen 2001); A haetulla prasina, mean value of 2 animals (Jørgensen 1988); Trachemys scripta (newly hatched), mean value of 2 animals (present study); Rattus norvegicus, mean value of 8 animals (Lindenlaub et al. 1995); Testudo graeca, mean value of 2 animals (Jørgensen 1988); Cryptomy sp., mean value of 8 animals (Lindenlaub et al. 1995); Spalax ehrenbergi, mean value of 8 animals (Lindenlaub et al. 1995); Trachemys scripta (sexuallly mature), mean value of 2 animals (present study); Cavia cobaya, mean value of 5 animals (Lindeman 1969b); Saimiri sciureus, mean value of 8 animals (Igarashi et al. 1975); Trachemys scripta, old (large) turtles, mean value of 2 animals (present study); Melopsittacus undulatus, mean value of 5 juveniles and 4 adults (Jørgensen 1991); Anguilla anguilla (Yellow eel) (Mathiesen 1985); Eretmochelys imbricata, mean value of 2 animals (Severinsen, personal observation); Synodontis nigriventris (Jensen 1994); Anguilla anguilla (Silver eel) (Mathiesen 1985); Melanosuchus niger, mean value of 2 juvenile animals (Jørgensen 1988); Columba livia, mean value of 7 animals (Rosenhall 1970); Catharacta skua (Jørgensen 1989);Corvus corone cornix (Jørgensen 1989); Homo sapiens, mean value of two studies by Rosenhall (1972) (13 individuals) and by Watanuki and Schukencht (1976) (2 individuals); Pluvialis apricaria (Jørgensen 1989) Tachyglossus aculetus, mean value of 3 animals (Jørgensen and Locket 1995). b. The $y$ axis shows the residuals of the total area of the utricular macula (UM) with respect to the regression line in a rescaled by a factor of 5 compared with $\mathbf{a}$. The $x$ axis represents the total number of hair cells (HCs) on a logarithmic scale. The various species of animals are clearly grouped phylogenetically. Melanosuchus niger (a crocodile) is found among the birds (Aves). The monotreme Tachyglossus aculeatus is isolated compared with other animals. Note that the turtles Trachemys scripta and Eretmochelys imbricata as well as the tortoise Testudo graeca are positioned near the two representatives of the primates - the monkey Saimiri sciureus and humans. Symbols as in a.

LM, which is similar to the findings of Jørgensen (1974).

When observing the surface of intact specimens in SEM, the opposite problem arises. Even though the cotillary, striolar, and rampary $\mathrm{HC}$ morphs clearly differ from one another, matters become more complex in the medial and lateral dividing lines of striola. In SEM, the transitional zone between the two extrastriolar regions is not sharp. On the contrary, it is graded and consists of 1-3 "chimera" cells whose regional origin is difficult to pinpoint. Combining these two methods offers a more nuanced but a more complex picture of striola and one method cannot be said to be superior to the other. From this it is possible to conclude that the most precise description of striola would be made by studying sections perpen-

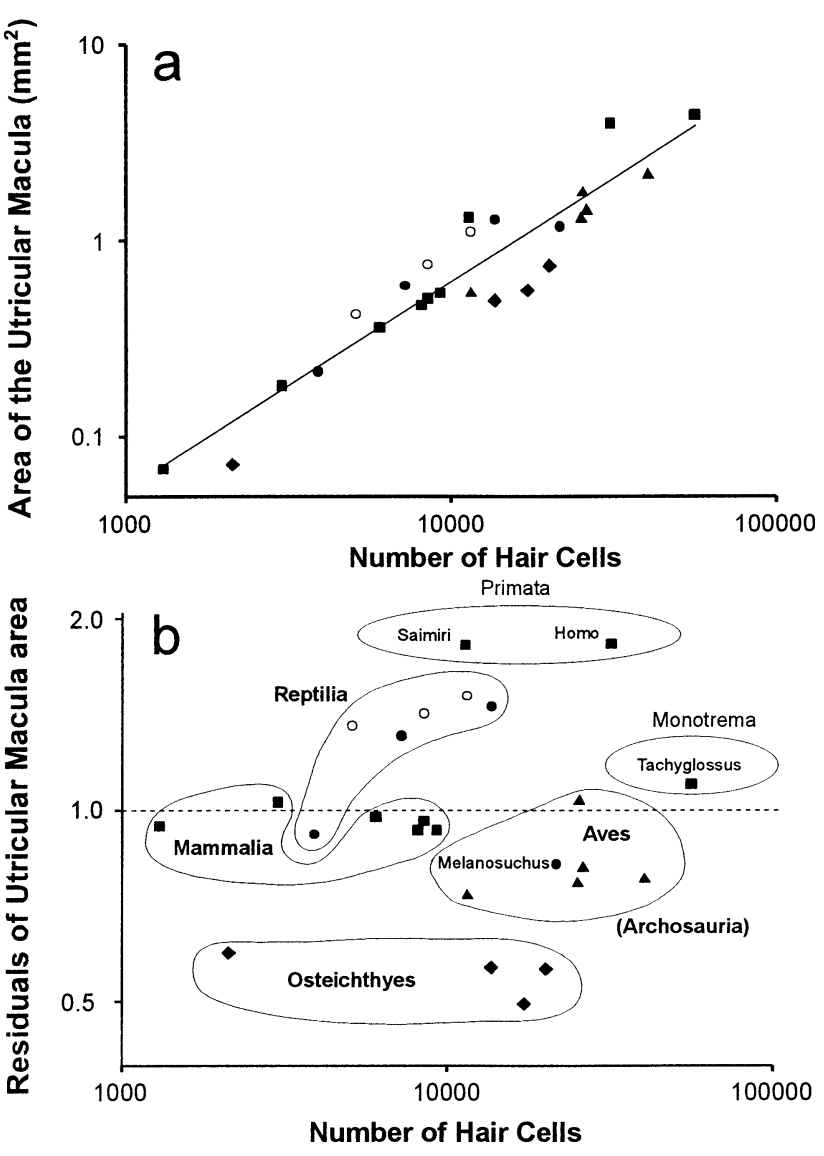

dicular to the surface of the UM using the transmission electron microscope (TEM), since this method allows for a synchronous observation of both apical structure and basal innervation.

\section{Total area and total number of HCs of the UM}

The area and the number of HCs of the UM are highly comparable to other turtle species (Fig. 8a). Compared to fish, birds, and small mammals, the HC density in the UM is relatively low. However, the density is remarkably similar to those found in primates. This observation is certainly interesting, but since interpretation of environmental stimuli depends on many factors such as brain integration, neural signal velocity, and most probably on subtle differences in the fine structure of the sensory epithelium, it is not possible to draw general conclusions about the functional significance of this observation.

Most interestingly, the species belonging to the same classes seem to be grouped phylogenetically (Fig. 8b). Trachemys seems to fit in very well in the group of its "cousins," the tortoise Testudo and the sea turtle Eretmochelys. The crocodile Melanosuchus is placed among the birds. Considering that the crocodiles in many aspects resemble birds more than they 
do other reptiles, e.g., the anatomy of their inner ear, their vocal communication, and the nursing of their offspring, this does not cause any wonder and hence the group is here termed Archosauria after the common ancestor of both crocodiles and birds. $\mathrm{Hu}-$ mans and the squirrel monkey Saimiri represent the Primata and are grouped furthest away from the regression line with the same residual value.

\section{Growth of the UM}

Growth of the inner ear sensory epithelium implies either an increase of the total area or an increase in the total number of HCs. Growth is positively correlated to the square root of the $P L$, which again is often related linearly to age but not always. Since the exact age of the turtles was not known and since weight is not always a valid estimator for growth in turtles, $P L$ was chosen as the best possible and most stable parameter. One should be cautious when including chronology as a fixed factor correlated to growth since growth patterns in turtles are extremely perplexing. Temperature during and after embryonic development has both direct and indirect effects on growth in turtles (Williamson et al. 1989; Rhen and Lang 1999), and other ecological factors such as food availability and quality are key elements in controlling growth (Cagle 1946; Gibbons et al. 1981). In general, however, when animals are kept under suitable conditions, the known growth spurt pattern in juvenile turtles (Cagle 1946; Sarnat et al. 1981; Limpus and Chaloupka 1997) can be correlated to the number of HCs and the area of the UM, since the area and number of HCs increase from $0.33 \mathrm{~mm}^{2}$ and $\sim 4000$ in prehatchlings to $0.5-0.65 \mathrm{~mm}^{2}$ and $\sim 5000-6000$ in juveniles. The area and number of HCs in large mature animals are $1.1 \mathrm{~mm}^{2}$ and $\sim 12,000$. Growth is highest just after the turtles hatch, and increments in HC number and area of the UM may reach 25\%-30\% within a short period of time. When sexual maturity is reached, growth of the turtle decelerates dramatically and reaches a maximum value asymptotically (Moll and Legler 1971) and growth of the UM seems to follow this pattern. In some specimens growth ceases completely (Cagle 1946, 1950). Furthermore, repeated observations show that senility often occurs in Trachemys scripta (Cagle 1944). Indeed the term "indeterminate growth" should be reconsidered since at least one study has shown that not all reptiles continue to grow throughout life (Gibbons 1990). High growth shortly after birth or hatching is also seen in some lower vertebrates (Corwin 1983) and birds (Goodyear et al. 1999). In mice, the percentage of HCs has been estimated to increase from $\sim 40 \%$ to $\sim 60 \%$ during the first four weeks postpartum. It should be noted, however, that these cells are prob- ably not "new" cells but rather transdifferentiated SCs (Rüsch et al. 1998).

The observation that inner ear sensory epithelia in lower vertebrates most often increase in area and number of HCs during life (Alfs and Schneider 1973; Lewis and Li 1973; Corwin 1983) thus also applies to reptiles, at least to the slider turtle. In contrast, in birds increase in area and $\mathrm{HC}$ population occurs only within the first few months after hatching (Goodyear et al. 1999). Likewise, in birds the relationship between HC number and the total area of the postembryonic UM appears to be very complex since no significant increase in area takes place during the first two weeks but the number of HCs increases by nearly 20\% (Goodyear et al. 1999). This implies that the HC densities vary throughout the ontogenesis of the birds but, even though the HC densities become lower with age, this does not mean that a reduction of the total HC population takes place. It simply indicates that the addition of HCs is not directly proportional to the growth of the rest of the sensory epithelium. This problem is coined "reference trap" and is applied to cases in which wrong conclusions have been drawn from densities alone (Brændgaard and Gundersen 1986). A similar complex growth pattern has been noticed in the saccular macula of the bullfrog Rana catesbeiana (Lewis and Li 1973). In mammals, there is no postembryonic increase in area (Werner 1933; Lindeman 1969b; Rosenhall 1972). Lastly, a mean reduction of $21 \%$ of the $\mathrm{HC}$ population has been observed in the UM of humans older than 70 years of age. Most interestingly, however, a few did not show any reduction (Rosenhall 1973).

Little is known about the growth pattern of the UM in any animal, but studies on fish and birds have shown highest $\mathrm{HC}$ densities in the peripheral (rampary) zone and the lowest densities in striola (Rosenhall 1970; Mathiesen 1985). Furthermore, the HC densities in turtles seem constant during development, which contrasts with earlier observations in amphibians and birds.

This study on utricular growth-along with studies on other vertebrate classes-highlights the importance of detailed knowledge of both regional $\mathrm{HC}$ density, total HC population, and total area of the sensory epithelium investigated. When working with densities alone, one should be most cautious to extrapolate observations in specific regions or in specific developmental stages of individuals into general conclusions on whole populations. The study on humans by Rosenhall (1973) shows that fetuses possess higher HC densities than postnatal individuals and also that a specific medial area of the UM exhibit low HC II densities in individuals between 71 and 95 years of age. This underlines the importance of obtaining knowledge of both the numerator and the denominator in 
the ratios (densities) before any valid estimations on growth patterns of an organ can be established.

\section{Formation of new HCs in the UM}

Small HCs have been described in the inner ear vestibular sensory epithelia of all vertebrates examined (Jørgensen 1970, 1975; Lewis and Li 1973, 1975; Corwin 1983; Mathiesen 1985; Rubel et al. 1995; Kirkegaard and Jørgensen 2000). It has also been observed that the stereovilli of small HCs are thinner than stereovilli on normal-sized HCs (Jørgensen 1970, 1975; Mathiesen 1985; Kirkegaard and Jørgensen 2000). Details concerning the architectural mechanisms which govern the apical development of small HCs with thin stereovilli have been given by Tilney et al. (1992). Furthermore, a TEM study on Daubenton's bat Myotis daubentonii has revealed that the small HCs are basally innervated (Kirkegaard and Jørgensen 2000). These observations, together with the fact that apoptotic HCs have been observed in representatives of all other vertebrate classes (Jørgensen 1981; Jørgensen and Mathiesen 1988; Jørgensen and Locket 1995; Kirkegaard and Jørgensen 2000; Jensen and Jørgensen 2001), strongly indicate that small HCs are early stages of functionally mature ones.

Since small HCs, as those observed in the present study, are found in all three regions of the UM, it seems plausible that new HCs are added intraepithelially. This has also been proposed in studies of a fish (teleost), a caecilian (amphibian), and birds (Mathiesen 1985; Jørgensen 1981; Jørgensen and Mathiesen 1988). However, it cannot be ruled out that some of the small observed HCs may represent mature HCs which are repairing their hair bundle or even belong to yet another subclass of mature HCs. In contrast, peripheral production of HCs has been proposed to be the main mechanism of $\mathrm{HC}$ addition in some end organs of elasmobranchs and anuran amphibians (Lewis and Li 1973; Corwin 1985b).

To sum up, HCs belonging to a specific region of the UM can be categorized by their apical structure, the shape of their surface, and their orientation. On the borders of striola, HCs II can most probably be distinguished from extrastriolar HCs II by their shorter kinocilia. Striolar HCs with a large free surface and a high number of stereovilli most probably are HCs I.

The observation of small HCs with thin stereovilli in all three regions, combined with the fact that 4000-5000 HCs are observed in small turtles compared with 12,000 in large ones, strongly indicates that postembryonic production of HCs indeed takes place in the UM of the slider turtle Trachemys scripta. Furthermore, HC production also seems to occur intraepithelially. Growth of the UM is positively correlated to the square root of the PL. The increase in number of HCs and area of the UM follows the growth spurt of juvenile turtles and continues at a high rate until the animal reaches sexual maturity, whereafter growth slows down. Finally, the fraction of each region of the UM and the mean area per $\mathrm{HC}$ are constant in animals of varying sizes.

\section{ACKNOWLEDGMENTS}

The assistance in sectioning by Dorte Olsson is much appreciated. Likewise, for skillful help in the creation of the figures, correction of the English text, and general support, Lise Mark is warmly thanked. Mette Kirkegaard gave highly valuable advice on the manuscript and Birgitte Dahl gave valuable comments on the English text. Both are sincerely thanked. The study received financial support from the Danish Natural Science Research Council (grant No. 51-000276), Fonden til Laegevidenskabens Fremme, and the Lundbeck Foundation, Denmark.

\section{REFERENCES}

Alfs B, SCHNEIDER H. Vergleichend-anatomische Untersuchungen am Labyrinth zentraleuropäisher Froschlurch-Arten (Anura) Z. Morph. Tiere. 76:129-143, 1973.

BAIRD IL. The anatomy of the reptilian ear. In: Gans C, Parsons TS (Eds.) Biology of the reptilia. Academic Press, London, pp 193275,1970 .

BrændgaARd H, Gundersen HJG. The impact of recent stereological advances on quantitative studies of the nervous system. J. Neurosci. Methods 18:39-78, 1986.

Burlet HM de. Vergleichende Anatomie des stato-akustischen Organs. Handb. Vergleichende Anat. Wirbeltiere 2:1293-1380, 1934.

Cagle FR. Sexual maturity in the female of the turtle Pseudemys scripta elegans. Copeia 3:149-152, 1944.

CAGLE FR. The growth of the slider turtle, Pseudemys scripta elegans. Am. Midland Naturalist 36:685-729, 1946.

Cagle FR. The life history of the slider turtle, Pseudemys scripta troostii (Holbrook) Ecol. Monogr. 201:31-54, 1950.

CORWIN JT. Postembryonic growth of the macula neglecta auditory detector in the ray, Raja clavata: continual increases in hair cell number, neural convergence, and physiological sensitivity. J. Comp. Neurol. 217:345-356, 1983.

CoRwIN JT. Auditory neurons expand their terminal arbors throughout life and orient toward the site of postembryonic hair cell production in the macula neglecta in elasmobranchs. J. Comp. Neurol. 239:445-452, 1985a.

CoRwIN JT. Perpetual production of hair cells and maturational changes in hair cell ultrastructure accompany postembryonic growth in an amphibian ear. Proc. Natl. Acad. Sci. USA 82:3911-3915, 1985b.

FLOCK $\AA$. Structure of the macula utriculi with special reference to directional interplay of sensory responses as revealed by morphological polarization. J. Cell Bio. 222:412-431, 1964. 
Gibbons JW. In: Shetfield R (Eds.)Life history and ecology of the slider turtle. Smithsonian Institution Press, Washington, DC, p 367.

Gibbons JW, Semlitsch RD, Greene JL, Schubauer JP. Variation in age at maturity of the slider turtle (Pseudemys scripta) Am. Naturalist 117:841-845, 1981.

Goodyear RJ, Gates R, Lukashin AN, Richardson GP. Hair-cell numbers continue to increase in the utricular macula of the early posthatch chick. J. Neurocytol. 28:851-861, 1999.

Gundersen HJG. Notes on the estimation of numerical density of arbitrary profiles: the edge effect. J. Microsc. 111:219-223, 1977.

Gundersen HJG. Stereology of arbitrary particles. A review of unbiased number and size estimators and the presentation of some new ones. J. Microsc. 143:3-45, 1986.

Gundersen HJG, Østerby R. Optimizing sampling efficiency of stereological studies in biology: Or "Do more less well. J. Microsc. 121:65-73, 1981.

Gundersen HJG, Jensen EBV, Kiêu K, Jensen J. The efficiency of systematic sampling in stereology-reconsidered. J. Microsc. 193:199-211, 1999.

Hunter-Duvar IM. An electron microscopic study of the vestibular sensory epithelium. Acta Otolaryngol. 95:494-507, 1983.

Igarashi M, Watanuki K, Miyata H, Alford B. Vestibular mapping in the squirrel monkey. Arch. Otorhinolaryngol. 211:153-161, 1975.

JENSEN JC. Structure and innervation of the inner ear sensory organs in an otophysine fish, the upside-down catfish (Synodontis nigriventris David) Acta Zool. (Stockh.) 752:143-160, 1994.

Jensen JC, JøRGensen JM. Dark hair cells in the inner ear of the rainbow trout. A study of the influence of different fixation methods. Acta Zool. (Stockh.) 82:79-88, 2001.

JøRGENSEN JM. On the structure of the macula lagenae in birds with some notes on the avian macula utriculi and saculi. Videnskabelige meddelelser fra Dansk Naturhistorisk Forening 133:121$147,1970$.

JøRGENSEN JM. The sensory epithelia of the inner ear of two turtles, Testudo graeca L. and Pseudemys scripta (Schoepff). Acta Zool. 55:289-298, 1974.

JøRGENSEn JM. The sensory epithelia in the inner ear of a lizard, Calotes versicolor Daudin. Videnskabelige Meddelelser fra Dansk Naturhistorisk Forening 138:7-19, 1975.

JøRGENSEN JM. On a possible hair cell turn-over in the inner ear of the caecilian Ichthyopis glutinosus (Amphibia: Gymnophiona) Acta Zool. 623:171-186, 1981.

JøRGENSEN JM. The number and distribution of calyseal hair cells in the inner ear utricular macula of some reptiles. Acta Zool. (Stockh.) 693:69-175, 1988.

JøRGENSEN JM. Number and distribution of hair cells in the utricular macula of some avian species. J. Morphol. 201:187204, 1989.

JøRGENSEN JM. Regeneration of lateral line and inner ear vestibular cells. Regeneration of vertebrate sensory receptor cells. Ciba Symp. 160:151-170, 1991.

Jørgensen JM, Andersen T. On the structure of the avian maculae. Acta Zool. 54:121-130, 1973.

Jørgensen JM, Christensen JT. The inner ear of the common rhea (Rhea americana L.). Brain Behav. Evol. 34:273-280, 1989.

Jørgensen JM, Locket NA. The inner ear of the echidna Tachyglossus aculeatus: the vestibular sensory organs. Proc. R. Soc. Lond. 260:183-189, 1995.

Jørgensen JM, Mathiesen C. The avian inner ear: Continuous production of hair cells in vestibular sensory organs, but not in auditory papilla. Naturwissenschaften 75:319-320, 1988.

KirkegaARd M, Jørgensen JM. Continuous hair cell turnover in the inner ear vestibular organs of a mammal, the Dauben- ton's bat (Myotis daubentonii) Naturwissenschaften 87:83-86, 2000.

KIRKEGAARD M, JøRGENSEN JM. The inner ear macular sensory epithelia of the Daubenton's bat. J. Comp. Neurol. 483:433-444, 2001.

LEWIS ER, Li CW. Evidence concerning the morphogenesis of saccular receptors in the bull frog (Rana catesbeiana) J. Morphol. 1393:351-362, 1973.

LewIS ER, Li CW. Hair cell types and distribution in the otolithic and auditory organs of the bullfrog. Brain Res. 83:35-50, 1975.

Limpus C, ChaloupKa M. Nonparametric regression modelling of green sea turtle growth rates (southern Great Barrier Reef) Oceanogr. Lit. Rev. 449:989.

Lindeman HH. Regional differences in structure of the vestibular sensory organs. J. Laryngol. Otol. 831:1-17, 1969a.

LindEMAN HH. Studies on the morphology of the sensory regions of the vestibular apparatus. Adv. Anat. Embryol. Cell Biol. 42:1$113,1969 \mathrm{~b}$.

Lindenlaub T, Burda H, Nevo E. Convergent evolution of the vestibular organ in the subterranean mole-rats, Cryptomys and Spalax, as compared with the aboveground rat, Rattus. J. Morphol. 224:303-311, 1995.

Lombarte A, Popper AN. Quantitative analyses of postembryonic hair cell addition in the otolithic endorgans of the inner ear of the European hake, Merluccius merluccius (Gadiformes, Teleostei) J. Comp. Neurol. 345:419-428, 1994.

Lowenstein O, Osborne MP, Wersäll J. Structure and innervation of the sensory epithelia of the labyrinth in the Thornback ray (Raja clavata) Proc. R. Soc. Lond. 160:1-12, 1964.

Malick LE, Wilson RB. Modified thiocarbohydrazide procedure for Scanning Electron Microscopy: Routine use for normal, pathological, or experimental tissues. Stain Technol. 504:65-269, 1975.

Mathiesen C. Structure and innervation of inner ear sensory epithelia in the European eel (Anguilla anguilla L.). Acta Zool. (Stockh.) 654:89-207, 1985.

Moll EO, Legler JM. The life history of a neotropical slider turtle, Pseudemys scripta (Schoepff), in Panama. Bull. Los Angeles County Mus. Nat. Hist. 11:1-102, 1971.

NyengaARd JR. Stereological methods and their application in kidney research. J. Am. Soc. Nephrol. 10:1100-1123, 1999.

Peterson EH, Cotton JR, Grant JW. Structural variation in cilliary bundles of the posterior semicircular canal. Ann. N Y Acad. Sci. 781:85-102, 1996.

Popper AN, Hoxter B. Growth of a fish ear: 1. Quantitative analysis of hair cell and ganglion cell proliferation. Hear. Res. 15:133142, 1984.

Retzius GDas Gehörorgan Der Wirbeltiere II. Samson and Wallin, Stockholm, 1884.

Rhen T, Lang JW. Temperature during embryonic and juvenile development influences growth in hatchling snapping turtles, Chelydra serpentina. J. Therm. Biol. 24:33-41, 1999.

Ricker WE. Linear regressions in fishery research. J. Fish. Res. Board Can. 30:409-434, 1973.

Rosenhall U. Some morphological principles of the vestibular maculae in birds. Arch. Klin. Exp. Ohr. Nas. Kehlk. Heilk. 197:154-182, 1970.

Rosenhall U. Vestibular macular mapping in man. Ann. Otol. Rhinol. Laryngol. 81:339-351, 1972.

Rosenhall U. Degenerative patterns in the aging human vestibular neuro-epithelia. Acta Otolaryngol. (Stockh.) 76:208-220, 1973.

Rubel EW, Dew LA, Roberson DW. Mammalian vestibular hair cell regeneration. Science 267:701-707, 1995.

RÜSch A, Lysakowski A, EATOCK RA. Postnatal development of type I and type II hair cells in the mouse utricle: Acquisition of voltage-gated conductances and differentiated morphology. J. Neurosci. 1818:487-7501, 1998. 
SARnat BG, McNabB E, Glass M. Growth of the turtle Chrysemys scripta under constant controlled laboratory conditions. Anat. Rec. 199:433-439, 1981.

Spoendurn HH. Ultrastructural studies of the labyrinth in squirrel monkeys. The role of vestibular organs in the exploration of space NASA, Washington, D.C., pp 7-22, 1965.

Tilney LG, Tilney MS, DeRosier DJ. Actin filaments, stereocilia and hair cells: How cells count and measure. Ann. Rev. Cell Biol. 8:257-274, 1992.

Watanuki K, Schuknecht HF. A morphological study of human vestibular sensory epithelia. Arch. Otolaryngol. 102:583-588, 1976.
Werner CIF. Die Differenzierung der Maculae im Labyrinth, insbesondere bei Säugetieren. Z. Anat. Entw. Gesch. 99:696-709, 1933.

WERSÄLL J. Studies on the structure and innervation of the sensory epithelium of the cristae ampullares in the guinea pig. Acta Otolaryngol. Suppl. (Stockh.) 126:1-85, 1956.

Wersäll J. Vestibular receptor cells in fish and mammals. Acta Otolaryngol. Suppl. (Stockh.) 163:24-29, 1960.

Williamson LU, Spotila JR, Standora EA. Growth, selected temperature and CTM of young snapping turtles, Chelydra serpentina. J. Therm. Biol. 14:33-39, 1989. 